\title{
Prescribing restrictions - a necessary strategy among some European countries to enhance future prescribing efficiency?
}

Brian Godman ${ }^{1,2,3}$, Rickard Malmström ${ }^{4}$, Marion Bennie ${ }^{5,6}$, Solveig Sakshaug ${ }^{7}$, Thomas Burkhardt ${ }^{8}$, Stephen Campbell ${ }^{9}$, Kristina Garuoliene ${ }^{10,11}$, Ulrich Schwabe ${ }^{12}$, Luka Vončina ${ }^{13}$, Lars L Gustafsson ${ }^{1}$

1 Department of Laboratory Medicine, Division of Clinical Pharmacology, Karolinska Institutet, Karolinska University Hospital Huddinge, SE 141 86, Stockholm, Sweden

Institute for Pharmacological Research "Mario Negri", Milan, Italy

Prescribing Research Group, University of Liverpool Management School, Chatham Street, Liverpool, UK

Department of Medicine, Clinical Pharmacology Unit, Karolinska Institutet, Karolinska University Hospital Solna, SE-17176, Stockholm Sweden

Strathclyde Institute for Pharmacy and Biomedical Sciences, University of Strathclyde, Glasgow, UK

Information Services Division, NHS National Services Scotland, Edinburgh, UK

Department of Pharmacoepidemiology, Division of Epidemiology, Norwegian Institute of Public Health, Oslo, Norway

Hauptverband der Österreichischen Sozialversicherungsträger, Vienna, Austria

Primary Care Research Group, University of Manchester, UK

Faculty of Medicine (Department of Pathology, Forensic Medicine and Pharmacology), University of Vilnius, Vilnius, Lithuania Medicines Reimbursement Department, National Health Insurance Fund, Vilnius, Lithuania

University of Heidelberg, Institute of Pharmacology, Heidelberg, Germany

Drugs and Medical Products, Croatian Institute for Health Insurance, Zagreb, Croatia

\section{Abstract}

The unsustainable growth in pharmaceutical expenditure has resulted in multiple initiatives across Europe to lower prices of generics and enhance their utilisation. These include prescribing restrictions. However, there have been concerns with their impact on subsequent quality of care as well as their influence in reality. OBJECTIVES: (a) Review the influence of prescribing restrictions and whether there are any differences depending on their nature and drug classes; (b) Ascertain whether prescribing restrictions can be added to existing demand-side measures to further enhance prescribing efficiency; (c) Whether they compromise subsequent quality of care. RESULTS: Prescribing restrictions have a variable impact on subsequent utilisation of patented protected products versus generics in a class, with their influence depending on the nature and follow-up of the restrictions rather than the class of drug. This is seen among the proton pump inhibitors, statins, and renin-angiotensin drugs. Prescribing restrictions can be successfully added to existing measures to further enhance prescribing efficiency, and do not appear to compromise subsequent quality of care. CONCLUSIONS: Prescribing restrictions can be a successful strategy as countries strive to maintain the European ideals for healthcare. However, care is needed when planning these programmes: else health authorities could be disappointed with their outcome.

\section{Keywords}

Pharmaceuticals; Prescribing restrictions; Generics; Drug utilisation studies; Efficiency

Corresponding author Brian Godman

Fax number +46858581070

Brian.Godman@ki.se
Disclosure

The majority of the authors are employed directly by health authorities or health insurance agencies or are advisers to these organisations. No author has any other relevant affiliation or financial involvement with any organisation or entity with a financial interest in or financial conflict with the subject matter or materials discussed in the manuscript. No writing assistance was utilised in the production of this manuscript. 


\section{Introduction}

There is growing scrutiny of pharmaceutical expenditures across Europe as this is the fastest growing cost component in ambulatory care, with pharmaceutical expenditures being now typically the largest or equalling the largest component in this sector across Europe [1-3]. The well known reasons for this growth include a growing elderly population, strict clinical targets, the continued launch of new premium priced medicines and rising patient expectations [1-6]. This unsustainable growth has resulted in increasing urgency among health authorities and health insurance companies across Europe to introduce additional reforms to further improve prescribing efficiency [1-9]. One of the objectives is to help maintain the European ideals of equitable and comprehensive healthcare without prohibitive increases in either taxes or health insurance premiums, which is especially important given current financial concerns in Europe.

Supply side reforms include pricing agreements for new drugs, compulsory price cuts, measures to obtain low prices for generics and delisting products from national reimbursement lists where they are no longer considered to be of value [1-3,5-12]. Demand side reforms for new drugs include measures to restrict their usage to sub-populations providing most value through for instance price: volume agreements with payback mechanisms, educational initiatives as well as monitoring prescribing against agreed indications; the latter often coupled with financial incentives or penalties for abuse [6-9,13-16]. Initiatives for existing drugs include measures to enhance the prescribing and dispensing of generics. These can be grouped under the 4 Es:

- Education such as academic detailing, prescribing guidance including an essential list of drugs such as the "Wise Drug List" in Stockholm County Council, Sweden, and benchmarking;

- Engineering incorporating disease management programmes, quality and prescribing targets;

- Economics incorporating financial incentives for pharmacists and physicians; and

- Enforcement including mandatory generic substitution and prescribing restrictions $[2,3,5-11,13,17$ 28].

Financial incentives have also been successfully used to reward physicians for addressing areas of concern with their prescribing [29,30], as well as treating patients to agreed clinical targets and care pathways [6,11,31-33]. Accompanying this, governments, health authorities and health insurance agencies have also instigated a variety of measures to address physician and patient concerns with the effectiveness and/or side-effects of generics when they occur [1,5,7-9,11,18,34]. The objective is to enable payers to take full advantage of estimated global sales of $\$$ US $100 \mathrm{bn} /$ year of products likely to lose their patents between 2008 and 2013 [35,36].

As discussed, prescribing restrictions are just one method currently employed by health authorities and health insurance agencies across Europe to enhance prescribing efficiency. However, there have been concerns with their influence in reality and whether their introduction will compromise future quality of care. Consequently, the objectives of this paper are:

- Firstly, to review the influence of prescribing restrictions on limiting the utilisation of patent protected products in three high volume classes; namely Proton Pump Inhibitors (PPIs), statins and ezetimibe, and renin-angiotensin drugs (Angiotensin Receptor Blockers - ARBs - versus generic Angiotensin Converting Enzyme Inhibitors - ACEIs), and whether there are any differences in their influence with different circumstances and classes. If so, the possible rationale for this;

- Secondly, to ascertain whether prescribing restrictions can be added to existing demand side measures to further enhance prescribing efficiency as typically health authorities and health insurance agencies introduce multiple reforms in quick succession;

- Thirdly, whether there have been any documented adverse effects of prescribing restrictions on the subsequent quality of care or expenditure in related product areas among health authorities and health insurance agencies. 
As a result, the principal aim of this paper is to answer the question whether prescribing restrictions do offer a suitable and continuing strategy for European countries to further enhance their prescribing efficiency as resource pressures grow.

\section{Results}

\section{Rationale}

Prescribing restrictions have typically been introduced among European countries where low cost alternatives exist in a class and the authorities believe that increasing their utilisation would enhance prescribing efficiency without compromising care in all or the majority of patients. As such, WHO recommendations have been endorsed: «Patients receive medications appropriate to their clinical needs, in doses that meet their own individual requirements, for an adequate period of time, and at the lowest cost to them and their community» [37].

Prescribing restrictions have been applied to PPIs, HMG CoA (3-hydroxy-3-methylglutaryl-coenzyme A) reductase inhibitors (statins) and the renin-angiotensin drugs (ACEIs and ARBs) as they meet these criteria as demonstrated by:

- PPIs: health authorities and health insurance agencies typically view all PPIs as having similar effectiveness. Consequently, they have instigated a number of reforms and initiatives to encourage the prescribing of the lowest cost alternative [1-3,5,8,10,11,17,38];

- Statins: health authorities and health insurance agencies again typically believe generic statins including generic simvastatin should be used as first-line treatment for patients with CHD and hypercholesterolaemia, with patent protected atorvastatin and rosuvastatin reserved for patients failing to achieve target lipid levels with simvastatin $[1-3,5,8,10,11,14,17,22,38]$. These beliefs are endorsed by IDEAL study, which failed to show a significant reduction in coronary vascular events for patients prescribed high dose atorvastatin $(80 \mathrm{mg} /$ day $)$ versus low dose simvastatin $(20 \mathrm{mg} /$ day) [39]. In addition, a recent ecological study showed that outcomes in terms of the subsequent impact of drug treatment on lipid levels were similar whether patients were prescribed formulary drugs (including generic simvastatin) versus non-formulary drugs, which included patent protected statins $[25,40]$. Published studies have also shown that patients can be successfully switched between statins without compromising care [41], and physicians in the UK extensively use generic simvastatin to achieve agreed target lipid levels in the Quality and Outcomes Framework to help maximise their income $[5,11,31,32]$.

- ACEIs/ARBs: some European countries introduced prescribing restrictions for the ARBs when first launched as the manufacturers failed to provide any data demonstrating increased effectiveness of ARBs versus ACEIs to support their request for premium pricing [6,20]. Alongside this, prospective clinical studies had shown coughing only occurred in approximately $10 \%$ of patients prescribed ACEIs [42,43]. In addition, only $2 \%$ to $3 \%$ of patients in the ACEI clinical trials actually discontinued these drugs due to coughing [42,44]. These findings led the Office of Fair Trading in the UK to suggest that ARBs should only comprise a maximum of 5\% of total prescriptions for all renin-angiotensin drugs, especially once generic ACEIs became available [45]. Having said this, published studies have shown that coughing can occur in up to $25 \%$ of patients in selected populations $[46,47]$. In addition, it may be difficult in practice to disassociate a patient's cough possibly due to an ACEI from any underlying disease such as a respiratory infection, which may enhance switching rates in reality as seen in Austria [20]. Alongside this, compliance is a concern among patients with asymptomatic diseases such as hypertension, which is reflected in an average mean reported compliance rate for antihypertensive drugs of only $64 \%$ in $80 \%$ of patients or more after one 
year [48]. Consequently, initiatives are increasingly directed towards encouraging the prescribing of generic ACEIs first line especially as a recent ecological study again showed that the outcomes, in terms of the subsequent impact of drug treatment on blood pressure, were similar whether patients were prescribed formulary drugs (including generic ACEIs) versus non-formulary drugs; the latter including patent protected ARBs $[25,40]$. However, patent protected ARBs can still be prescribed second line where there are concerns with side effects.

The published studies to date demonstrate that prescribing restrictions appear to have a variable influence on subsequent drug utilisation patterns. In addition, subsequent drug utilisation patterns appear to be influenced more by the nature and extent of the restrictions, including their follow-up, rather than the product class itself $[5,6,14,17-22]$. This is illustrated by the differences in the influence of prescribing restrictions on the utilisation of patent protected statins (atorvastatin and rosuvastatin) once generic statins became available among three European countries, which arose from different prescribing requirements. A similar situation is seen with the utilisation of ARBs following the instigation of prescribing restrictions. However, both of these situations are different to the more limited influence of prescribing restrictions for esomeprazole in Norway. Prescribing restrictions have though been successful in limiting the utilisation of PPIs in Central and Eastern European countries $[3,28]$.

\section{Statins}

In Austria, a 66\% reduction in the utilisation of atorvastatin and rosuvastatin was seen three full years following the introduction of prior authorisation prescribing restrictions in 2004 (Table I) [17]. This compares with a 44\% reduction in Norway two full years after the introduction of restrictions in 2005 and from a higher starting point ( $46 \%$ vs. $32 \%$ of total statin utilisation on a Defined Daily Dose - DDD - basis), where there is greater trust in physicians' prescribing habits [5] (Table I). DDDs are defined as «the average maintenance dose of a drug when used on its major indication in adults» [49,50]. There was a similar influence of the prescribing restrictions in Finland to that seen in Austria, with a 59\% reduction in the utilisation of atorvastatin and rosuvastatin 1.2 years after prescribing restrictions were introduced [5,14]. This was helped by physicians in Finland required to specify on the prescription that either atorvastatin or rosuvastatin does represent second-line treatment before these two statins can be reimbursed [5,14].

These initiatives (Table I) led to increasing prescribing efficiency with expenditure on statins decreasing by 3\% in Austria between 2001 and 2007 despite a 144\% increase in utilisation (2008 DDDs) [17]. In Norway, expenditure on statins decreased by $55 \%$ from $€ 26,551 / 1,000$ inhabitants/year in 2004 to $€$ 12,050 in 2009 [5]. This was again despite an appreciable increase in utilisation from 57.3 DDDs/1,000

AT - Physicians must have the permission of the Chief Medical Officer of the patient's Social Insurance Fund

(Austria) before atorvastatin is reimbursed (rosuvastatin second line from launch)

- Patients are required to fully fund the prescription ( $100 \%$ co-payment) if no prior authorisation requested or granted

NO - Physicians are trusted to write the rationale for prescribing atorvastatin in the patient's notes following

(Norway) the restrictions (rosuvastatin not reimbursed during the period of the quoted study). This could though be followed up by the Norwegian National Insurance System

- Specific permission was needed from the authorities during the study period if physicians wished to prescribe lower strength atorvastatin $(10$ and $20 \mathrm{mg}$ ) and the patients be reimbursed, the objective being to encourage greater prescribing of simvastatin at higher strengths before prescribing atorvastatin second line

Table I. Restrictions for atorvastatin and rosuvastatin prescribing in Austria and Norway $[5,17]$ 
inhabitants per day (2010 DDDs) in 2004 to 101.5 DDDs/1,000 inhabitants per day in 2009. This was helped by the instigation of the "Stepped-price model" for generics [23], which resulted in an $85 \%$ price reduction for generic simvastatin versus originator prices [5].

\section{ACEIs/ARBs}

The introduction of prescribing restrictions for ARBs in Austria and Croatia to second line in patients unable to tolerate ACEIs reduced their utilisation versus countries with currently limited demand side measures such as Portugal $[6,20]$ (Table II). A similar situation was seen in Lithuania where ARBs were included in the Reimbursement List from 2004. However, they could only be prescribed by cardiologists and only for patients unable to tolerate ACEIs, with frequent monitoring of prescriptions including the prescriber and indication [Gauroliene K, unpublished data].

However, the influence of prescribing restrictions appeared greater in Croatia than Austria (Table II). We believe this was aided in Croatia by physicians from the Croatian Institute for Health Insurance Agency visiting their colleagues in ambulatory care whom they suspect of abusing ARB prescribing restrictions, with the potential for financial penalties [6]. In Austria under the terms of the restriction, ARBs should only be prescribed in patients unable to tolerate ACEIs such as unacceptable coughing $[6,20]$. However, there is no prior authorisation scheme unlike the situation for the statins [17].

These differences in utilisation patterns (Table II) were again reflected in appreciable differences in reimbursed expenditure in 2007 when adjusted for population sizes $(€ / 1,000$ inhabitants/year). This was $€ 8,459$ in Croatia compared with $€ 26,620$ in Portugal [6].

\begin{tabular}{|ccccccccc|}
\hline Utilisation \% per country & 2001 & 2002 & 2003 & 2004 & 2005 & 2006 & 2007 \\
\hline Austria & 85 & 82 & 81 & 79 & 78 & 76 & 75 \\
Croatia & 98 & 97 & 94 & 91 & 88 & 86 & 87 \\
Portugal & 80 & 75 & 71 & 67 & 64 & 60 & 56 \\
\hline
\end{tabular}

Table II. ACEl utilisation as a percentage of total renin-angiotensin utilisation 2001 to 2007 (DDD basis - 2010 DDDs) [6]

\section{PPIs}

There was though only limited influence of prescribing restrictions on the utilisation of esomprazole in Norway following their introduction in February 2007 (Table III). Prescribing restrictions were introduced due to the high acquisition costs of esomeprazole versus the other PPIs, namely omeprazole, pantoprazole and lansoprazole, no major demonstrable therapeutic difference between the various

\begin{tabular}{|ccccccccc|}
\hline $\begin{array}{c}\text { Utilisation (DDDs/1,000 } \\
\text { inhabitants per day) }\end{array}$ & 2003 & 2004 & 2005 & 2006 & 2007 & 2008 & 2009 \\
\hline Esomeprazole & 10.17 & 11.95 & 13.64 & 16.25 & 13.73 & 13.4 & 14.34 \\
\hline Other PPIs & 10.28 & 10.27 & 10.84 & 10.87 & 16.06 & 19.68 & 21.38 \\
\hline Total PPIs & 20.45 & 22.22 & 24.48 & 27.12 & 29.79 & 33.08 & 35.72 \\
\hline
\end{tabular}

Table III. Utilisation of esomeprazole 2003 to 2009 in Norway versus other PPIs (DDDs/ 1,000 inhabitants per day) - 2010 DDDs [5] 
PPIs, and esomeprazole being one of the highest expenditure products in Norway in 2006 [5,23]. Under this scheme, lansoprazole, omeprazole and pantoprazole should be prescribed first line as the "preferred products" unless there is a good medical rationale [5,23].

We believe this limited impact of prescribing restrictions for esomeprazole in Norway arose because specialists have to verify the diagnosis and recommend therapy before PPIs are prescribed and reimbursed in the community, and they are not subject to the same restrictions. In addition, GPs (General Practitioners) may be reluctant to alter the advice if esomeprazole is recommended by specialists [5]. However, it is difficult to substantiate this without further research. In any event, this limited impact is more likely due to the regulations surrounding reimbursement rather than the actual class of drug; especially since, as discussed, health authorities believe there are no major differences in effectiveness between the various PPIs $[2,3,5,11,38]$.

\section{General comments}

The need to consider all aspects when introducing prescribing restrictions is further illustrated by the situation in Germany with respect to utilisation of statins and ezetimibe following the introduction of reference pricing for the statins in 2004 [2,38,51]. This followed a review of the literature in which the authors could find no major differences in outcomes between the various statins; however, considerable differences in acquisition costs once generic simvastatin became available [38,51]. After its introduction, utilisation of atorvastatin fell from 55\% of total statin DDDs in 2002 to just $2 \%$ in 2007 [51]. This followed the removal of atorvastatin from the social health insurance reimbursement list with the manufacturer reluctant to lower its price to that approaching generic simvastatin. As a result, total expenditure on statins in Germany 2007 among the Social Health Insurance patients was $€ 480.5$ $\mathrm{mn}, 57 \%$ below 2003 levels (pre-reference pricing). This was despite a 77\% increase in utilisation (DDD basis -2007 DDDs) [51]. However, the reduced marketing of statins following generic availability and Level 2 reference pricing resulted in increasing expenditure on ezetimibe and fixed dose ezetimibe/ simvastatin combinations. Combined sales of ezetimibe alone or in combination were $€ 192 \mathrm{mn}$ in 2007 [51]. This was despite concerns regarding their ability to further reduce CV events versus simvastatin alone, which led the Regional Sickness Funds and Physician Associations to include ezetimibe and its combinations in a "me-too" list of patented drugs [51]. This list contains patented drugs that appear to have no additional therapeutic benefit versus current treatments and higher costs/DDD. Recent court rulings have endorsed the position of the editors of the "me-too" list, with the manufacturers of ezetimibe/simvastatin combination subsequently withdrawing the lawsuit against the inclusion of this product on the "me-too" list [52].

The published studies have also shown that prescribing restrictions can be added to existing demandside measures to further enhance prescribing efficiency. This is welcomed as health authorities and health insurance agencies typically seek to introduce a number of initiatives simultaneously, or in quick succession, to improve prescribing efficiency $[2,3,5,10,11,17,19]$. This is illustrated by the influence of prescribing restrictions for patented protected statins in Austria and Norway, which built on existing demand-side measures $[5,17]$. This was also illustrated in Sweden where the reimbursement agency (TLV) recently introduced prescribing restrictions for ARBs to limit their prescribing to second line in patients unable to tolerate ACEIs [19]. This built on existing measures among the regional County Councils to reduce ARB prescribing, which included prescribing guidance, prescribing targets and financial incentives $[8,25]$. In the published study, the number of patients initiated on ARBs decreased by $24 \%$ in the four months following prescribing restrictions, whilst increasing for ACEIs and calcium channel blockers, by $14 \%$ and $12 \%$, respectively [19]. The proportion initiated on ARBs having first been prescribed an ACEI within 24 months prior to an ARB also increased from 51\% to 67\%. As a result, total expenditure for anti-hypertensive drugs decreased by $4.7 \%$ to $€ 73$ million in SeptemberDecember 2008 compared to the same period in 2007 [19]. 
The various published studies also suggest it is unlikely there will be any negative impact on subsequent care with the introduction of prescribing restrictions. As mentioned, a recent ecological study showed that outcomes in terms of the impact of drug treatment on lipid levels and blood pressure were similar whether patients were prescribed formulary drugs (including generic simvastatin or generic ACEIs) versus non-formulary drugs, including patent protected statins and ARBs, in the Stockholm County Council "Wise Drug" List $[25,40]$. The major issue is long term compliance particularly with asymptomatic conditions such as hypercholesterolaemia and hypertension, which can have a profound influence on long term outcomes [48,53]. Consequently, the considerable resources released from increased prescribing of generic statins and ACEIs can be used to improve compliance. As a result, help appreciably reduce for instance subsequent cardiovascular events associated with the prescribing of statins versus any minor differences in effectiveness between them $[5,11,22,38,39]$.

Finally, the prescribing restrictions for the PPIs that typically exist among Central and Eastern European countries, e.g. in Croatia PPIs are only reimbursed where $\mathrm{H}_{2}$-blockers are no longer working for oesophageal reflux, alternatively for Zollinger-Ellison syndrome or eradication of Helicobacter pylori and in Lithuania only for reflux oesophagitis, duodenal ulceration or eradication of Helicobacter pylori, limited their utilisation (reimbursed) versus Western European countries [2,3,28]. As a result, provide guidance to Western European countries struggling to reduce their over-utilisation of PPIs, especially following recent concerns with the side effects from their long term use [11,54-58].

\section{Conclusions}

Prescribing restrictions have been successfully introduced across classes in Europe to help optimise the use of resources following the availability of generics in a class or related classes. This has been achieved without appearing to compromise subsequent care. In addition, the findings in Austria (statins), Norway (statins) and Sweden (ACEIs/ ARBs) suggest that prescribing restrictions can be introduced at any time to further enhance prescribing efficiency. However they have to be carefully considered. This includes their nature and follow-up as well as the potential impact on the prescribing of drugs in related therapeutic classes. Otherwise, health authorities and health insurance agencies could be disappointed with the outcome.

In countries where it is difficult to introduce prescribing restrictions, published studies have shown that the intensive combination of education, engineering and economics (please see Introduction for definitions and examples) can produce similar increases in the utilisation of generics versus patent protected products. As a result, offer an alternative approach if needed. This is seen with similar increases in the utilisation of generic statins once available in Sweden and UK versus those seen in Austria and Norway [1-3]. In Scotland for instance, intensive demand side initiatives (education, engineering and economics) limited ARB utilisation matching the patterns seen in Austria and Croatia with their prescribing restrictions (Table II) [6]. These intensive initiatives also resulted in reimbursed expenditure for the statins in Scotland up only 7\% in 2010 compared with 2001 levels despite a 6.2 fold increase in their utilisation during this period. This improvement in prescribing efficiency was helped by generic simvastatin being only $3 \%$ of pre-patent loss prices in 2010 [59].

In conclusion, prescribing restrictions do appear to offer health authorities and health insurance agencies the opportunity to further enhance prescribing efficiency without compromising care. As a result, help fund increased drug volumes with ageing populations and new drugs without appreciable increases in either taxes or health insurance premiums, as well as programmes to enhance compliance. Consequently, prescribing restrictions are likely to continue or even grow to benefit all key stakeholder groups, including physicians and patients, as resource pressures grow. The alternative is 
Questions for further research

How can we accelerate countries learning from each other to better plan for the introduction of prescribing restrictions rather than asking each country to undertake its own studies before undertaking any refinement. reduced monies available to fund increasing volumes and new innovative drugs, which is in no one's interests. Greater pro-activity generally pre-patent loss will also help maximising efficiency gains once generics are available, enhancing potential funding for new premium priced drugs [33]. However, this is countrydependent.

\section{The review in brief}

$\begin{array}{ll}\text { Clinical question } & \begin{array}{l}\text { Prescribing restrictions do offer a suitable and continuing strategy for European countries to further } \\ \text { enhance their prescribing efficiency as resource pressures grow? The situations of PPIs, statins, ARBs } \\ \text { and ACEls are analyzed. }\end{array} \\ \begin{array}{ll}\text { Type of review } & \text { Narrative. } \\ \text { literature } & \text { We conducted a narrative review of published articles selected from the extensive number of } \\ \text { publications and associated references known to the co-authors from across Europe concerning the } \\ \text { instigation of prescribing restrictions and their influence. These were subsequently combined with web- } \\ \text { based articles or internal health authority/health insurance articles known to the co-authors that had } \\ \text { eluded the initial selection. } \\ \text { There has been no review of the quality of the papers included in this review article using for instance } \\ \text { criteria developed by the Cochrane Collaboration [30]. This is because some of the references are } \\ \text { from web based articles. Nevertheless they have been included as they were typically written by } \\ \text { payers or their advisers, which are the principal intended audience for this paper. In addition, this } \\ \text { paper is primarily an opinion article to stimulate future debates on these important issues rather than a } \\ \text { thorough review of the literature. }\end{array} \\ \begin{array}{l}\text { Prescribing restrictions do appear to offer health authorities and health insurance agencies the } \\ \text { opportunity to further enhance prescribing efficiency without compromising care. However, care is } \\ \text { needed with their planning, implementation and follow-up; otherwise, health authorities could be } \\ \text { disappointed with the outcomes. }\end{array} \\ \begin{array}{l}\text { There are opportunities for countries to learn from each other. However, each country needs to } \\ \text { carefully consider the opportunities and logistics involved with introducing prescribing restrictions } \\ \text { versus other potential methods to enhance prescribing efficiency. }\end{array}\end{array}$

\section{Acknowledgements}

The authors would like to acknowledge the help of INFARMED for the provision of NHS data from Portugal, and the following collaborators:

- Iain Bishop, Information Services Division, NHS National Services Scotland, Edinburgh, UK

- Julie Lonsdale, Medicines Management, North Lancashire Teaching PCT, Lancaster, UK

- Christian Berg. Department of Pharmacoepidemiology, Division of Epidemiology, Norwegian Institute of Public Health, Oslo, Norway

- Björn Wettermark, Department of Laboratory Medicine, Division of Clinical Pharmacology, Karolinska Institutet, Karolinska University Hospital Huddinge, Stockholm, Sweden and Department of Pharmacoepidemiology, University Hospital Solna, Stockholm, Sweden

- Vera Vlahovič- Palčevski, Unit for Clinical Pharmacology, University Hospital Rijeka, Rijeka, Croatia This study was in part supported by grants from the Karolinska Institutet. 


\section{References}

1. Godman B, Shrank W, Wettermark B, Andersen M, Bishop I, Burkhardt, et al. Use of generics - a critical cost containment measure for all healthcare professionals in Europe? Pharmaceuticals (Basel) 2010; 3: 2470-94; doi 10.3390/ph/3082470

2. Godman B, Shrank W, Andersen M, Berg C, Bishop I, Burkhardt, et al. Comparing policies to enhance prescribing efficiency in Europe through increasing generic utilization: changes seen and global implications. Expert Rev Pharmacoecon Outcomes Res 2010; 10: 707-22

3. Godman B, Shrank W, Andersen M, Berg C, Bishop I, Burkhardt T, et al. Policies to enhance prescribing efficiency in Europe: findings and future implications. Frontiers Pharmacol 2011; 1: 1-16; doi: 10.3389/fphar.2010.00141

4. Garattini S, Bertele V, Godman B, Haycox A, Wettermark B, Gustafsson LL. Enhancing the rational use of new medicines across European healthcare systems - A Position Paper. Eur J Clin Pharmacol 2008; 64: 1137-8

5. Godman B, Sakshaug S, Berg C, Wettermark B, Haycox A. Combination of prescribing restrictions and aggressive generic pricing policies - an alternative approach to conserve resources? Expert Rev Pharmacoecon Outcomes Res 2011; 11: 121-9

6. Vončina L, Strizrep T, Godman B, Bennie M, Bishop I, Campbell S, et al. Influence of demandside measures to enhance renin-angiotensin prescribing efficiency in Europe: implications for the future. Expert Rev Pharmacoecon Outcomes Res 2011; 11: 469-79

7. Godman B, Bucsics A, Burkhardt T, Haycox A, Seyfried H, Wieninger P. Insight into recent reforms and initiatives in Austria; implications for key stakeholders. Expert Rev Pharmacoecon Outcomes Res 2008; 8: 357-71

8. Godman B, Wettermark B, Hoffman M, Anderson K, Haycox A, Gustafsson LL. Multifaceted national and regional drug reforms and initiatives in ambulatory care in Sweden; global relevance. Expert Rev Pharmacoecon Outcomes Res 2009; 9: 65-83

9. Sermet C, Andrieu V, Godman B, Van Ganse E, Haycox A, Reynier JP. Ongoing pharmaceutical reforms in France; implications for key stakeholder groups. Appl Health Econ Health Policy 2010; 8: 7-24

10. Coma A, Zara C, Godman B, Agusti A, Diogene E, Wettermark B, et al. Policies to enhance the efficiency of prescribing in the Spanish Catalan Region: impact and future direction. Expert Rev Pharmacoecon Outcomes Res 2009; 9: 569-81

11. McGinn D, Godman B, Lonsdale J, Way R, Wettermark B, Haycox A. Initiatives to enhance the efficiency of statin and proton pump inhibitor prescribing in the UK; impact and implications. Expert Rev Pharmacoecon Outcomes Res 2010; 10: 73-85

12. Vončina L, Strizrep T. Croatia: 2009/2010 pharmaceutical pricing and reimbursement forum. $E u-$ rohealth 2011; 16: 20-2

13. Adamski J, Godman B, Ofierska-Sujkowska G, Osinska B, Herholz H, Wendykowska K, et al. Review of risk sharing schemes for pharmaceuticals: considerations, critical evaluation and recommendations for European payers. BMC Health Serv Res 2010; 10:153; doi:10.1186/1472-6963-10-153

14. Martikainen J, Saastamoinen L, Korhonen M, Enlund H, Helin-Salmivaara A. Impact of restricted reimbursement on the use of statins in Finland. Med Care 2010; 48: 761-6

15. Wettermark B, Godman B, Andersson K, Gustafsson LL, Haycox A, Bertele V. Recent national and regional drug reforms in Sweden - implications for pharmaceutical companies in Europe. Pharmacoeconomics 2008; 26: 537-50

16. Wettermark B, Godman B, Eriksson C, van Ganse E, Garattini S, Joppi R, et al. Einführung neuer Arzneimittel in europäische Gesundheitssysteme. GGW 2010;10: 24-34 (Introduction of new medicines into European healthcare systems) 
17. Godman B, Burkhardt T, Bucsics A, Wettermark B, Wieninger P. Impact of recent reforms in Austria on utilisation and expenditure of PPIs and lipid lowering drugs; implications for the future. Expert Rev Pharmacoecon Outcomes Res 2009; 9: 475-84

18. Wettermark B, Godman B, Jacobsson B, Haaijer-Ruskamp F. Soft regulations in pharmaceutical policymaking - an overview of current approaches and their consequences. Appl Health Econ Health Policy 2009; 7: 137-47

19. Wettermark B, Godman B, Neovius M, Hedberg N, Mellgren TO, Kahan T. Initial effects of a reimbursement restriction to improve the cost-effectiveness of antihypertensive treatment. Health Policy 2010; 94: 221-9

20. Godman B, Buscics A, Burkhardt, Schmitzer M, Wettermark B, Wieninger P. Initiatives to enhance renin-angiotensin prescribing efficiency in Austria; impact and implications for other countries. Expert Rev Pharmacoecon Outcomes Res 2010; 10: 199-207

21. Fretheim A, Håvelsrud K, MacLennan G, Kristoffersen DT, Oxman AD. The effects of mandatory prescribing of thiazides for newly treated, uncomplicated hypertension: interrupted time-series analysis. PLoS Medicine 2007; 4 (e232): 1178-86

22. Sakshaug S, Furu K, Karlstad Ø, Rønning M, Skurtveit S. Switching statins in Norway after new reimbursement policy - a nationwide prescription study. Br J Clin Pharmacol 2007; 64: 476-81

23. Festöy H, Sveen K, Yu LM, Gjönnes L, Gregersen T. Norway - Pharmaceutical Pricing and Reimbursement Information. October 2008. Available at: http://ppri.oebig.at/Downloads/Results/ Norway_PPRI_2008.pd (last accessed October 2011]

24. Spanninger G, Vogler S, Habl C, Rosian-Schikuta I, Leopold C, Wieninger P. Pharmaceutical Pricing and Reimbursement Information - Austria (September 2007). Available at: http://ppri.oebig. at/Downloads/Results/Austria_PPRI_2008.pdf (last accessed October 2011)

25. Gustafsson LL, Wettermark B, Godman B, Andersén-Karlsson E, Bergman U, Hasselström J, et al. The "Wise List"- A comprehensive concept to select, communicate and achieve adherence to recommendations of essential drugs in ambulatory care in Stockholm. Basic Clin Pharmacol Toxicol 2011; 108: 224-33

26. Diogène E, Figueras A. What public policies have been more effective in promoting rational prescription of drugs. J Epidemiol Community Health 2011; 65: 387-8

27. Godman B, Wettermark B, Bennie M, Diogène E, Van Ganse E, Gustafsson LL. Critical role for clinical pharmacologists and hospital pharmacists with enhancing prescribing efficiency for new and existing drugs [In Press - E Hospital - The Official Journal of the European Association of Hospital Managers]

28. Garuoliene K, Godman B, Gulbinovič J, Wettermark B, Haycox A. European countries with small populations cannot obtain low prices for drugs - Lithuania as a case history to contradict this. Expert Rev Pharmacoecon Outcomes Res 2011; 11: 341-7

29. Wettermark B, Pehrsson A, Juhasz-Haverinen, Veg A, Edlert M, Törnwall-Bergendahl G, et al. Improving the quality and efficiency of drug prescribing in primary care by means of financial incentives. Pharmacoepidemiol Drug Saf 2009: 18: S261

30. Sturm H, Austvoll-Dahlgren A, Aaserud M, Oxman AD, Ramsay CR, Vernby Å, et al. Pharmaceutical policies: effects of financial incentives for prescribers (Review). Cochrane database of Systematic Reviews Issue 3. Art No.: CD006731 DOI: 10.1002/14651858. CD006731 2007

31. Roland M. Linking Physicians' Pay to the Quality of Care - A Major Experiment in the United Kingdom. New Engl J Med 2004; 351: 1448-54

32. Doran T, Fullwood C, Gravelle H, Reeves D, Kontopantelis E, Hiroeh U, et al. Pay-for-performance programs in family practices in the United Kingdom. New Engl J Med 2006; 355: 375-84

33. Moon J, Flett A, Godman B, Grosso A, Wierzbicki A. Getting better value from the NHS drug budget. BMJ 2011; 342: 30-2 
34. Duerden M, Hughes D. Generic and therapeutic substitutions in the UK: are they a good thing? $\mathrm{Br}$ J Clin Pharmacol 2010; 70: 335-41

35. Frank RG. The ongoing regulation of generic drugs. N Engl J Med 2007; 357: 1993-6

36. Jack A. Balancing Big Pharma’s books. BMJ 2008; 336: 418-9

37. World Health Organisation. Promoting rational use of medicines: core components. September 2002. Available at: http://apps.who.int/medicinedocs/pdf/h3011e/h3011e.pdf (last accessed October 2011)

38. Godman B, Haycox A, Schwabe U, Joppi R, Garattini S. Having your cake and eating it: Office of Fair Trading proposal for funding new drugs to benefit patients and innovative companies. Pharmacoeconomics 2008; 26: 91-8

39. Pedersen TR, Faergeman O, Kastelein JJ, Olsson AG, Tikkanen MJ, Holme I, et al; Incremental Decrease in End Points Through Aggressive Lipid Lowering (IDEAL) Study Group. High-dose atorvastatin vs usual-dose simvastatin for secondary prevention after myocardial infarction: the IDEAL study: a randomized controlled trial. JAMA 2005; 294: 2437-45

40. Norman C, Zarrinkoub R, Hasselström J, Godman B, Granath F, Wettermark B. Potential savings without compromising the quality of care. Int J Clin Pract 2009: 63:1320-6

41. Usher-Smith J, Ramsbottom T, Pearmain H, Kirby M. Evaluation of the clinical outcomes of switching patients from atorvastatin to simvastatin and losartan to candesartan in a primary care setting: 2 years on. Int J Clin Pract 2008; 62: 480-4

42. Fletcher A, Palmer A, Bulpitt C. Coughing with angiotensin converting enzyme inhibitors; how much of a problem? J Hypertens 1994; 12: S43-S47

43. NHS. PCT prescribing report (November 2009). Prescribing of angiotensin-converting-enzyme (ACE) inhibitors and angiotensin-II receptor antagonists (AIIRAs) - Prescribing guidance and discussion points. Available at: http://www.nhsbsa.nhs.uk/Documents/PPDPCTReports/pctreport_20092.pdf(last accessed October 2011)

44. Frisk P, Mellgren T-O, Hedberg N, Berlin A, Granath F, Wettermark B. Utilisation of angiotensin blockers in Sweden combining survey and register data to study adherence to prescribing guidelines. Eur Jn Clin Pharmacol 2008; 64: 1223-9

45. Office of Fair Trading. Current price inefficiencies and potential benefits of value-based pricing. February 2007. Available at: http://www.oft.gov.uk/shared_oft/reports/comp_policy/oft885m.pdf (last accessed October 2011)

46. Elliot H. Focus on the ONTARGET results. J Hypertens 2009; 27: S8-S10

47. McDowell S, Coleman J, Ferner RE. Systematic review and meta-analysis of ethnic differences in risks of adverse reactions to drugs used in cardiovascular medicine. BMJ 2006; 332: 1177-81

48. Cramer JA, Benedict A, Muszabek N, Keskinaslan A, Khan ZM. The significance of compliance and persistence in the treatment of diabetes, hypertension and dyslipidaemia: a review. Int J Clin Pract 2008; 62: 76-87

49. World Health Organization (WHO). Guidelines for ATC classification and DDD assignment 2009. Oslo: WHO Collaborating Centre for Drug Statistics Methodology. Available at: http://www. whocc.no (last accessed October 2011]

50. World Health Organization (WHO). Introduction to Drug Utilisation Research. WHO International Working Group for Drug Statistics Methodology, WHO Collaborating Centre for Drug Statistics Methodology, WHO Collaborating Centre for Drug Utilization Research and Clinical Pharmacological Services. ISBN 924156234 X (NLM classification: WB 330) Available at: http:// www.who.int/medicines/areas/quality_safety/safety_efficacy/Drug\%20utilization\%20research. pdf (last accessed October 2011]

51. Godman B, Schwabe U, Selke G, Wettermark B. Update of recent reforms in Germany to enhance the quality and efficiency of prescribing of proton pump inhibitors and lipid lowering drugs. Pharmacoeconomics 2009; 27 : 435-8 
52. Schwabe U, Paffrath D (eds.). Arzneiverordnungs Report 2011. Heidelberg: Springer Medizin Verlag (in press)

53. Ruokoniemi P, Korhonen M, Helin-Salmivaara A, Lavikainen P, Jula A, Junnila SY, et al. Statin adherence and the risk of major coronary events in patients with diabetes: a nested case-control study. Br J Clin Pharmacol 2011; 71: 766-76

54. Yang YY, Lewis J, Epstein S, Metz DC. Long-term proton pump inhibitor therapy and risk of hip fracture. JAMA 2006; 296: 2947-53

55. Gulmez S, Holm A, Frederiksen H, Jensen TG, Pedersen C, Hallas J. Use of proton pump inhibitors and the risk of community-acquired pneumonia: a population-based case-control study. Arch Intern Med 2007; 167: 950-5

56. Choudry M, Soran H, Ziglam H. Overuse and inappropriate prescribing of proton pump inhibitors in patients with Clostridium difficile-associated disease. QJM 2008; 101: 445-8

57. Leaonard J, Marshall JK, Moavvedi P. Systematic review of the risk of enteric infection in patients taking acid suppression. Am J Gastroenterol 2007; 102: 2047-56

58. Katz MH. Failing the acid test - benefits of proton pump inhibitors may not justify the risks for many users. Arch Intern Med 2010; 170: 747-8

59. Bennie M, Godman B, Bishop I, Campbell S. Multiple initiatives continue to enhance the prescribing efficiency for the PPIs and statins in Scotland [Accepted for publication in Expert Review Pharmacoeconomics and Outcomes Research] 